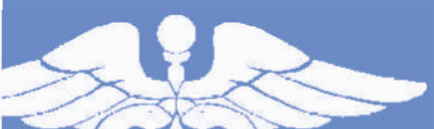

ISSN: 2782-7550 (Print) ISSN: 2782-7542 (Online)
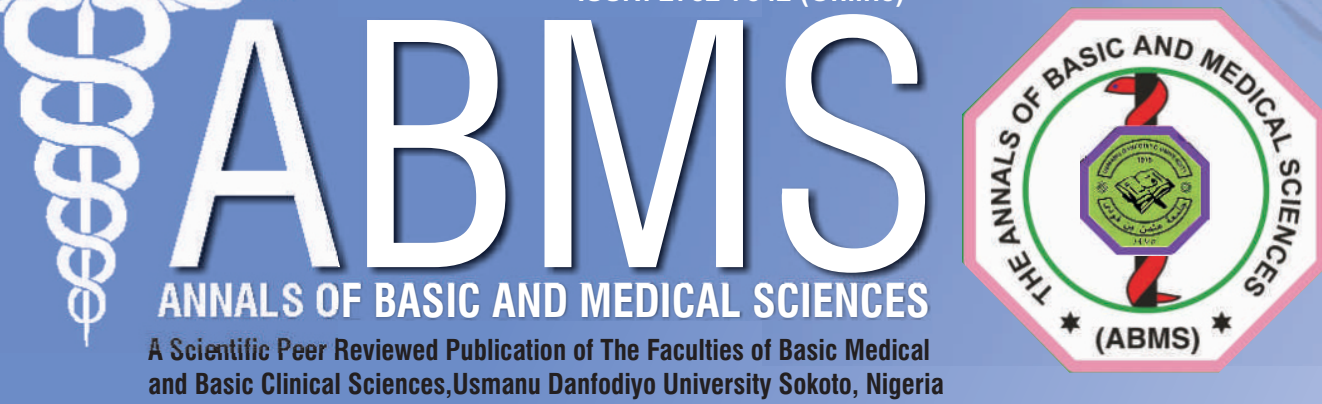

and Basic Clinical Sciences,Usmanu Danfodiyo University Sokoto, Nigeria
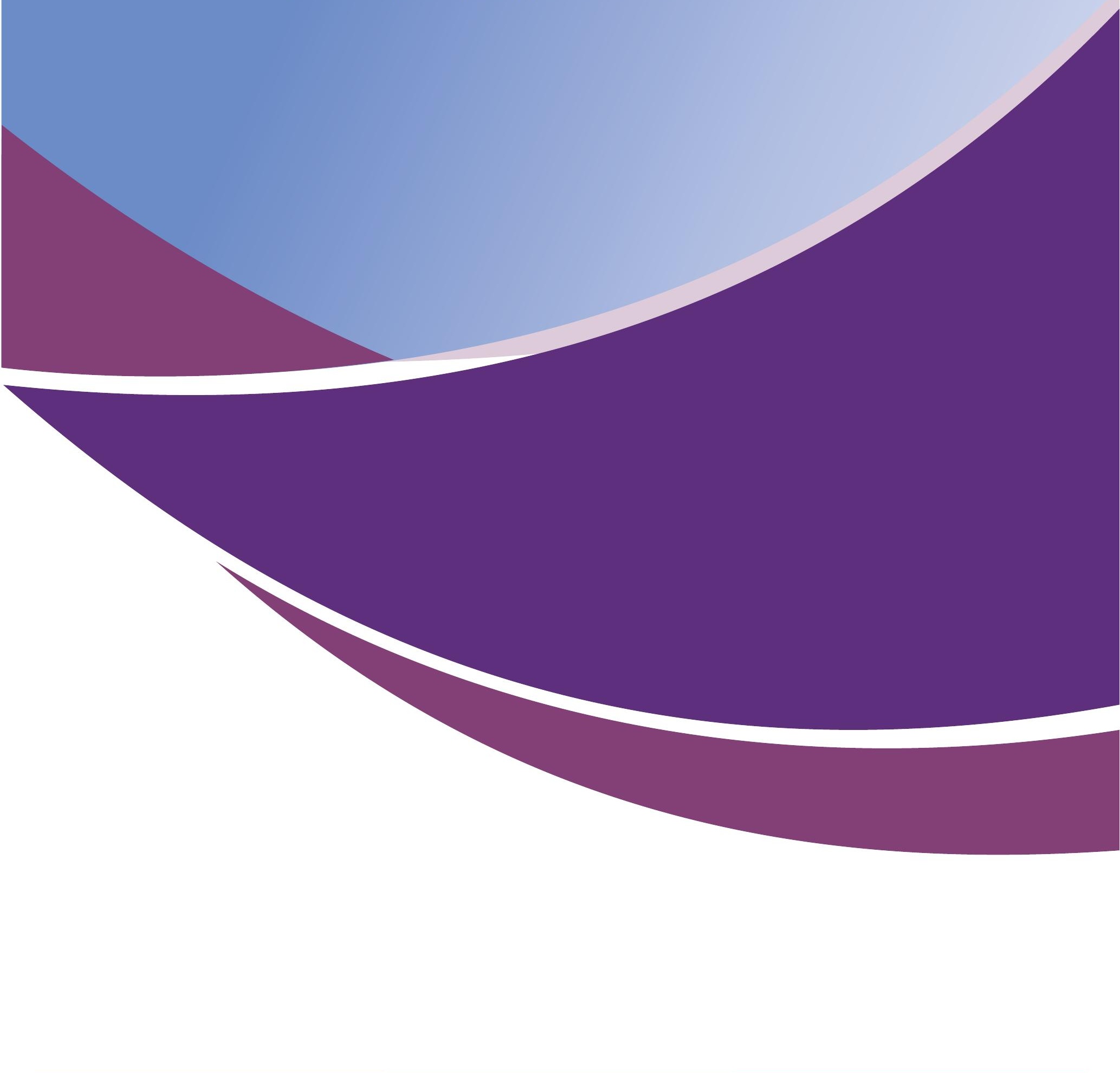


\title{
Global Innovation in Measles Vaccine Delivery: Focus on Sub-Saharan Africa
}

\author{
Mohammed Yahaya $^{1 *}$, Galalain Salma Muhammad ${ }^{2}$ \\ 'Department of Medical Microbiology and Parasitology, Faculty of Basic Clinical Science, College of Health Sciences \\ ${ }^{3}$ Department of Biological Sciences, Faculty of Sciences, Usmanu Danfodiyo University, P.M.B. 2254, Sokoto.
}

\begin{abstract}
:
Background: The Global Measles Elimination Program was initiated in the year 2000 with a target of 90 and 80 percent vaccine coverages at national level and local levels respectively by the end of 2015 . The target was later reviewed to year 2020. However, despite the availability of an effective measles vaccine for over five decades, this target has not been reached in most African countries with outbreaks of measles occurring periodically. Consequently, an innovative measles vaccine delivery mechanisms and technologies are necessary and timely for achieving measles elimination targets especially in Africa and globally at large. We set out to review publications and researches made in the area on global innovative approaches for measles vaccine delivery and their applicability in African setting.
\end{abstract}

Methods: We used the Preferred Reporting Items for Systematic Review and Meta-Analysis (or 'PRISMA') guidelines to search the PubMed, Cochrane database, African Journals Online and Google Scholar for articles reporting on the innovative approaches to Measles vaccine delivery between January 2010 to January 2019. Twentytwo eligible articles were considered for the qualitative synthesis.

Results: We identified 4948 publications, of which only 22 were eligible. The reviewed papers showed that microneedles patches have been developed to eliminate the need for syringes, diluents and accessories in measles vaccine delivery, another innovation is the use of aerosolized measles vaccine delivery using puff inhalers. Thermo stable vaccines to eliminate the need for cold chain and improve vaccine potency are another positive area. One $(4.5 \%)$ study each reported on micro-needle patches, thermostable vaccines, mono-dose prefilled vaccine delivery, vitamin A supplementation to improve measles vaccine coverage and improvement in access to vaccine. Two $(9.2 \%)$ studies reported on each of second dose of measles vaccination. Three (13.7\%) studies reported on pulmonary/aerosol vaccination and community engagement. Nine (40.9\%) studies reported on vaccine delivery to infants at age less than 9 months.

Conclusion: Our results elucidated innovative approaches to measles vaccine delivery that revolves around the microneedle patches, pulmonary/aerosol vaccination, thermostable vaccine, mono-dose prefilled vaccine delivery. Other areas involved given considerations for vaccine delivery to infants at age less than 9 months and given second dose of measles vaccination. Vitamin A supplementation, community engagements and use of information technology improves measles vaccine coverage.

Keywords: Innovations, Measles, Vaccines, Elimination, Africa

Corresponding author:

Mohammed Yahaya Department of Medical Microbiology and Parasitology, Faculty of Basic Clinical Sciences Email: yahyakt@yahoo.com Tel: +2348036867478
Introduction

M easles is one of the major childhood killer diseases among the under-fives especially from countries of Sub-Saharan Africa. (1) In 2010, there were at least 139, 300 deaths globally attributed to measles; this when translated further indicates about 380 deaths every day and more precisely 15 deaths every hour. (1) Measles occurs because of failure to vaccinate eligible children despite the availability of safe, effective vaccine. (2) Over the past 30 years most countries in SubSaharan Africa have relied on a single dose of Measles vaccination given at 9 months to protect children against Measles. (2)

A single dose of measles is not enough to attain at least $95 \%$ coverage, with $>90 \%$ coverage needed to build herd immunity. (3) Only $85 \%$ of children who receive MCV1 will seroconvert, necessitating an opportunity to revaccinate and protect the $15 \%$ who failed to seroconvert. The second dose will provide opportunity to vaccinate children who missed the first dose in the first year of life. (3) Currently, $70 \%$ of all measles cases of all measles cases are among children under 5 years of age who missed being vaccinated in the first year of life, hence the need to provide an opportunity for them to be vaccinated within the second year of life. The mortality and morbidity from measles and the cost of conducting SIAs in response to frequent measles outbreaks will be reduced with the introduction of MCV2 into the routine immunization schedule. (3) Measles elimination is still a problem for most countries. Elimination of Measles is defined as the absence of continuous measles transmission for more than 12 months. The United States of America was able to achieve this elimination target in the year 2000 following a robust effective vaccination program and other control 
measures even though vaccine hesitancy is now fueling massive measles resurgence in the country. (4)

The World Health Organization (WHO) global measles elimination strategy by 2020 has identified that measles elimination should be within the context of strengthening routine immunization service delivery coupled with upgrading research and innovation to this aspect. (5)

There are limited reference laboratories in Africa that can diagnose Measles when they do occur and resources for outbreak management are usually difficult to mobilize. There are various vaccine delivery methods developed and some are under development that if utilized properly by countries of Sub-Saharan Africa would revolutionized measles immunization to a next and better level. (6)

Objectives: The objectives of this manuscript are to review publications and researches made in the area of innovations towards the delivery of measles vaccine with a focus on Sub-Saharan Africa.

\section{Methodology}

Overview of study protocol: The systematic review was conducted in line with the preferred reporting Items for systematic reviews and meta-analysis (or 'PRISMA') guidelines. (7) The protocol for this study was developed by the authors and the full version is available on request

Search strategy: We searched Google Scholars, Medline, African Journals Online (AJOL), PubMed and Cochrane Library for articles published from 01 January 2010 to 01 January 2019. The search terms used were "innovations" OR "new advancements" OR "new technology" AND "Measles vaccine delivery.'

Study selection criteria: Articles were included for the review provided they reported on innovations or new technologies used in Measles vaccine delivery and were published from January 2010 to January 2019. We included articles irrespective of whether they were review papers, expert opinion or from original data, clinical trials as per as they were from human subjects.

Selection procedure: The titles and abstracts of all search results were listed and were thereafter reviewed to identify papers for full text review. The selection procedure is outlined in Figure 1. We excluded duplicate articles and publications reporting the same data. We also excluded articles that were not within the purview of Measles or Vaccination. Further exclusions were for articles that use animal models, outbreaks investigations of Measles and surveillance data on Measles. The review included articles written only in the English language. We also excluded articles whose full text versions were not available online. We obtained the full text of potentially relevant studies and scrutinized them independently for inclusion into our study.

Data extraction: A database was created in which the study name, study period, major innovation identified was recorded as applicable (Table 1). These were subsequently included in the qualitative synthesis for the review.

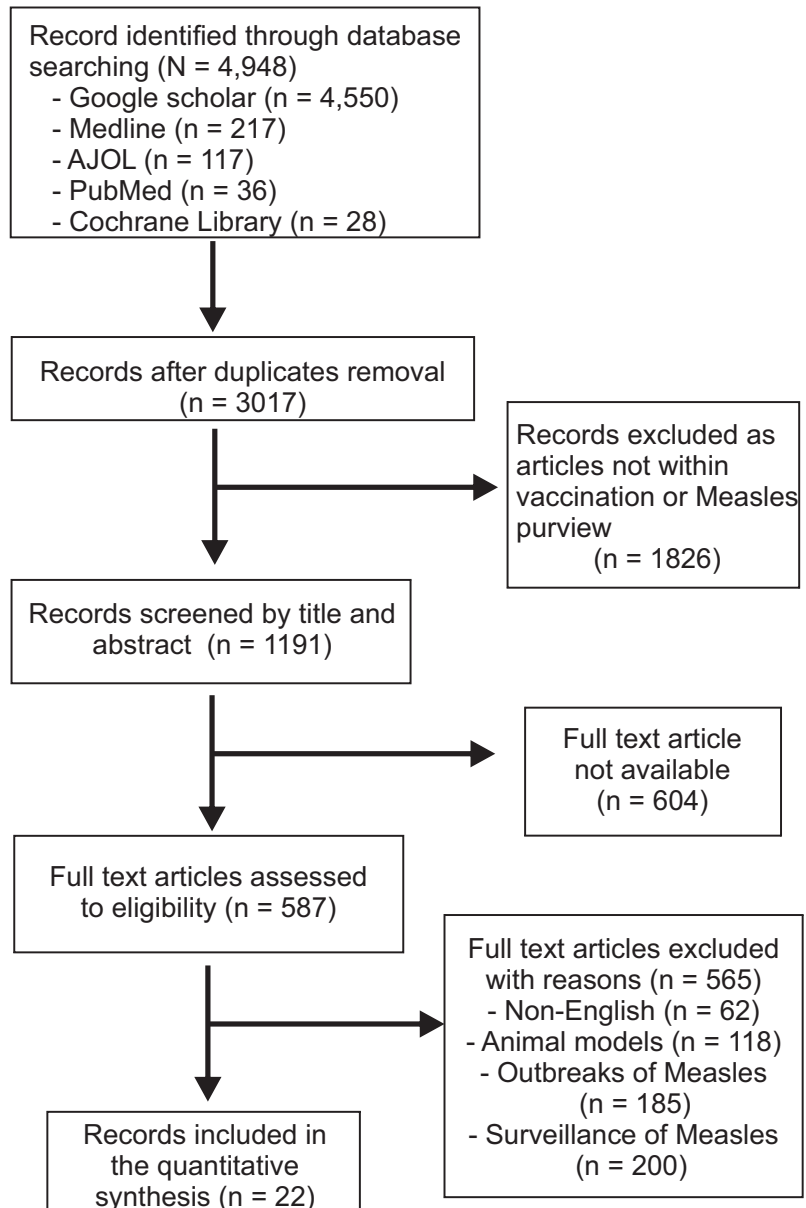

Figure 1: Summary of study selection procedure

Attempt to reduce bias: An attempt to reduce bias within studies and between individual studies was done via group independent joint review process by scanning list of articles as well as data utilized for the qualitative synthesis.

Analysis approach: The extracted data were reported as outlined by the authors using thematic areas considering innovative approaches in Measles vaccine delivery and its applicability to Africa where possible.

\section{Results}

Microneedle patches: Recently, the microneedle technology has been developed that consist of metal/polymer micron size needles pre-layered with measles vaccine for ease of administration into the dermis. This technology eliminates the need for the use of vaccine diluents, needle and syringes, availability of skilled workforce and the use of cold chain. Additionally, this technology can be effectively used in African setting because of its affordability as demonstrated by a study by Adhikari et al where they reviewed the cost effective- 
Table 1: Database referenced for the systematic review with their major points on innovation

\begin{tabular}{|c|c|c|c|c|}
\hline $\mathrm{S} / \mathrm{N}$ & Study name & $\begin{array}{l}\text { Study } \\
\text { Period }\end{array}$ & Ref & Measles vaccine delivery innovation(s) from the study \\
\hline 1 & $\begin{array}{l}\text { Balogun M.R., et. } \\
\text { al. }\end{array}$ & 2012 & $(34)$ & $\begin{array}{l}\text { Caregivers were more willing to receive SMS reminders and phone calls as against } \\
\text { internet based reminders for child immunization services. }\end{array}$ \\
\hline 2 & $\begin{array}{l}\text { Akinrinade O.T., } \\
\text { et. al }\end{array}$ & 2018 & (35) & $\begin{array}{l}\text { Caregivers were willing to receive SMS reminders compared to phone calls for child } \\
\text { immunization services }\end{array}$ \\
\hline 3 & Gera T., et. al. & 2016 & $(29)$ & $\begin{array}{l}\text { There is no effect of integration of health service like Vitamin A supplementation on } \\
\text { Measles coverage from trials in India and Bangladesh although a trial from } \\
\text { Tanzania reported a reverse finding }\end{array}$ \\
\hline 4 & Sievers R.E., & 2015 & $(9)$ & $\begin{array}{l}\text { Successful phase I trial of a 'puff haler' based aerosolized dry powder measles } \\
\text { vaccine with similar efficacy and no side effect compared to the subcutaneous } \\
\text { based vaccine }\end{array}$ \\
\hline 5 & Aaby P.,et. al. & 2012 & $(15)$ & $\begin{array}{l}\text { Cohort of children vaccinated at age less than } 9 \text { months have significant } \\
\text { protection against measles }\end{array}$ \\
\hline 6 & $\begin{array}{l}\text { Woudenberg T., } \\
\text { al. }\end{array}$ & 2017 & $(16)$ & $\begin{array}{l}\text { Children vaccinated at age } 6 \text { months have reduced incidence of measles } \\
\text { compared with their unvaccinated cohort }\end{array}$ \\
\hline 7 & Saeterdal I.et. al. & 2014 & $(32)$ & $\begin{array}{l}\text { Face to face community engagement strategies influence measles vaccine } \\
\text { uptake among large communities }\end{array}$ \\
\hline 8 & Flu L.Y., et. al., & 2016 & (33) & Monetary reward has minimal improvement in measles vaccination coverage \\
\hline 9 & Pagliusi S.et. al., & 2015 & (11) & $\begin{array}{l}\text { Novel primary needle free formulations can improve access and utilization of } \\
\text { vaccines by minimizing the cold chain requirements }\end{array}$ \\
\hline 10 & Pagliusi S.et. al., & 2017 & $(31)$ & $\begin{array}{l}\text { Concerted partnership between countries and regular and timely supply of } \\
\text { vaccines can facilitate measles eradication }\end{array}$ \\
\hline 11 & Bhatti U.A.,et. al., & 2018 & $(36)$ & $\begin{array}{l}\text { Data mining algorithm from hospital record coupled with geographic information } \\
\text { information system can help to classify areas into low(red) immunization } \\
\text { coverage and high (green) immunization coverage for the purpose of planning } \\
\text { and tracking defaulters }\end{array}$ \\
\hline 12 & $\begin{array}{l}\text { Adhikari B.B., et. } \\
\text { al. }\end{array}$ & 2016 & (8) & $\begin{array}{l}\text { The microneedle patch administration of measles is more cost effective } \\
\text { compared to the conventional measles vaccine administration }\end{array}$ \\
\hline 13 & Low N., et. al., & 2015 & $(10)$ & $\begin{array}{l}\text { Aerosolized measles vaccine administration was not superior to subcutaneous } \\
\text { measles vaccine administration from a cohort of children in a randomized } \\
\text { clinical trial }\end{array}$ \\
\hline 14 & Aaby P.,et. al. & 2010 & $(18)$ & Measles vaccination at 4.5 months has beneficial effects \\
\hline 15 & Jensen KJęt. al. & 2014 & (19) & Early measles vaccination induce protective biomarkers among recepients \\
\hline 16 & Do VA.,et. al., & 2017 & $(20)$ & $\begin{array}{l}\text { Measles vaccination at less than } 9 \text { months of age was associated with reduced } \\
\text { morbidity }\end{array}$ \\
\hline 17 & Martins C.et. al., & 2014(a) & $(21)$ & Measles vaccination at 4.5 and 9 months respectively, protective antibody \\
\hline 18 & Martins CL.et. al., & 2014(b) & $(22)$ & $\begin{array}{l}\text { Measlesvaccination at } 4.5 \text { and } 9 \text { months respectively reduce hospital } \\
\text { admission }\end{array}$ \\
\hline 19 & Njie Jobe J.et. al., & 2012 & (23) & $\begin{array}{l}\text { Early Measles vaccination induces CD4T cell response and antibody } \\
\text { development }\end{array}$ \\
\hline 20 & Fisker AB.et. al., & 2018 & (24) & Early Measles vaccination does not reduce mortality \\
\hline 21 & Brønd M.,et. al., & 2018 & $(27)$ & $\begin{array}{l}\text { Second dose of Measles vaccination reduce rate of hospitalization among } \\
\text { children }\end{array}$ \\
\hline 22 & Martins C.et. al., & 2013 & (28) & $\begin{array}{l}\text { Second dose of Measles vaccination induce protective antibody levels } \\
\text { among children }\end{array}$ \\
\hline
\end{tabular}

ness of using the conventional measles vaccine delivery system versus the use of microneedle patches. They found out a saving of United States $\$ 0.7$ dollars can be made per dose in favour of the microneedle patches. The microneedle patches may also eliminate vaccine wastage rate associated with the conventional measles vaccination as the conventional vaccine has a shelf life of six hours once reconstituted. (8)

Pulmonary/Aerosol vaccination: Sievers and colleagues reported a successful phase I trial among 60 volunteers following the administration of a single dose 'puff haler' aerosolized vaccine against measles using dry powder with no major side effects and with similar efficacy to the conventional subcutaneous vaccine in use. [9] The milestone development of aerosolized pulmonary 'puff haler' measles vaccination as reported by Sievers and colleague if utilized by African countries would likely improve measles vaccine coverage by eliminating the need of a skilled workforce hence minimizing resources, eliminating the need of needle or sterile water for injection leading to reduction in injection site infection and minimizing resources. (9) 
Even though there was an inconsistent result from a randomized control trial in 2015 that depicted greater level of antibody protection $(94.6 \%)$ to children immunized with the subcutaneous measles vaccination as compared to the aerosolized vaccination (85.4\%). (10) Several advances have been made thereafter in terms of the vaccine immunogenicity and recommended margin of safety for administration to overcome this. In a meeting of the developing countries vaccine manufacturers' network in India, D. Zehrung provided an overview on how novel primary needle free formulations can improve access and utilization of vaccines by minimizing the cold chain requirements that are mostly suboptimal in developing countries thereby improving vaccine coverage. (11)

It is consequently imperative for African countries to come together and request the vaccine manufactures to align their vaccine developments with the recommendation of the WHO on packaging to promote Africa's peculiarities. (12)

Thermostable vaccine: The Measles vaccine is among the vaccines that are most sensitive to heat/sunlight and even a minute exposure would lead to loss of potency that is permanent and irreversible. Therefore, the development of a thermostable vaccine that does not rely on cold chain would improve vaccine efficacy. (13)

Mono-dose prefilled vaccine delivery: Monodose prefilled vaccination is an innovative approach to vaccine delivery that minimizes or eliminates the risk of contamination and vaccine wastages even though there is the attendant increase in space and cost per dose. (14)

Vaccine delivery to infants at age less than 9 months: Aaby and colleagues in a review of secondary data demonstrated from multiple studies that cohort of infants vaccinated at less than 9 months of age had significant protection compared with the unvaccinated group. (15)

An observational cohort study from the Netherlands by Woudenberg et al also demonstrated that infants vaccinated as early as six month of age had lower risk of measles compared with their unvaccinated cohort. (16) The assumed optimal age for vaccination against measles was placed at nine months of age or greater. The basis behind this policy is the notion that measles vaccination below nine months of age is not immunogenic because of maternal antibodies that were still active hence it would hamper seroconversion. However, there is demonstrable evidence to suggest that the basis for such policy on seroconversion alone was wrong. Studies have demonstrated child survival and decrease risk of acquisition of measles infection even at a younger age. African countries that have areas with periodic outbreaks of measles would benefit for a review of policy for vaccination at age less than nine month of age. (16) The initial vaccine used against Measles in the 1960s was the inactivated Measles vaccine but it was discontinued duetoits poor immunogenicity. At present, a live attenuated vaccine is utilized via injection at 9 and 15 month of age. There are new vaccines under trails that use macaques' animal model and a viral proteins component of the $\mathrm{H}, \mathrm{F}$ and $\mathrm{V}$ that could be delivered at an earlier age and would be effective. (17)

Aaby and colleagues reported that given measles vaccination at 4.5 and 9 months of age has beneficial effect on child survival particularly for the girl child.(18) Similarly, Jensen and colleagues found out an increase levels of protective biomarkers among female child that were recipient of vitamin A compared to their male counterparts at an early age. (19)

Do and colleagues conducted a randomized trials among 1592 children and were able to elucidate that early measles vaccination before the 9 months of age was associated with reduced morbidity in the following months. (20) In two separate studies by Martin et al among children from Guinea Bissau with measles vaccination given at 4.5 and 9 months respectively, protective antibody was detected at 4.5 months (21) and there was also reduction in hospital admission compared to the control group that did not received early administration of measles vaccines. 22 Njie-Jobe et al vaccinated children at 4 months; 9 months and a booster dose at 36 months. They noted that early vaccination induced a predominant CD4 T cell response and associated rapid development of antibody after the booster doses.(23)

A contrary finding was recorded by Fisker et al from a two center randomized trial of an additional early dose of measles vaccine. It was shown that early measles vaccination does not reduce all cause mortality. (24)

\section{Second Dose of Measles Vaccination}

The administration of the second dose of measles vaccine (MCV2) has long been associated with increased seroconversion among children less than 2 years to attain the critical herd immunity of greater than $95 \%$. (25) However, the administration of this second dose was hampered by the WHO criteria for MCV2 introduction which requires countries to have $>80 \%$ coverage of MCV1 at the national level for 3 consecutive years. Fortunately, this criterion was lifted in 2016 by the SAGE Working Group on Measles \& Rubella.(26)

Countries are now eligible to enroll for the MCV2 regardless of their MCV1 coverage. This is a welcome development for countries in the sub-Saharan Africa who generally have low MCV1 coverage with few exceptions. It was not until the year 2013 that Kenya qualified for the MCV2 introduction.

Brond and colleagues conducted a randomized trial of two versus one dose of measles and they were able to deduce that two dose measles vaccination reduce rate of hospitalization among the recipients. (27) Martins et al were able to show from a randomized trial among children in Guinea Bissau that two doses of measles vaccine consisting of Edmonston-Zagreb and Schwarz vaccine given to children were able to induce protective antibody levels of $99 \%$ in children. (28) 
Vitamin A supplementation versus measles vaccine coverage: A Cochrane review by Gera and colleagues on the integrated management of childhood illness (IMCI) strategy evaluated two cluster-randomized trials from India and Bangladesh that estimated the effect of vaccine coverage for measles versus combination of other services like supplementation with vitamin $A$, exclusive breastfeeding and found little or no effect even though a similar review from Tanzania was able to find positive effect of the integration of health services like supplementation with vitamin A versus measles vaccine coverage. [29] The Cochrane review by Gera and colleagues where integration of health services found no effect with measles vaccine coverage from two studies in India and Bangladesh must be taken with caution from countries in Africa. This is probably so, because these studies were all from Asia with a different demographic and child health seeking behavior and more so in African countries like Nigeria, vitamin A supplementation is an integral part of the expanded program on immunization. [30] There is need for further studies on this from Africa to ascertain the true nature of this association so that it can lead to policy change and possibly diversion of scare resources that were hitherto allocated to vitamin A supplementation to measles elimination.

Improve access to vaccine: In 2015, the WHO American region became the first to be declared free of measles. This was achieved through concerted partnership between countries of the region and by maintaining a regular supply of vaccines through a demand forecasting system. (31)

Community Engagement: Saeterdall LS et al evaluated trials used for communication with the caregivers and communities like public meeting, radio talks, leaflets and face-to-face reviews on the effect for vaccine uptake. (32) They evaluated a trial from Pakistan and India on large group shows that this community-based strategy (especially face to face communications) increase the proportion of children vaccinated against measles and diphtheria, pertussis and tetanus but not against poliomyelitis vaccine. (32) There are novel approaches about community engagement strategies meant to increase community buy in to strengthen measles immunization.

These studies show that one on one communication with caregivers and communities would improve measles vaccine uptake. This is probably so because it allows clarifications and questions from the health worker to the caregiver.

Another study by Flu LY et al accessed use of monetary reward (pay for performance) versus immunization vaccine (measles inclusive) coverage. (33) Their finding revealed minimal change for objective improvement of routine immunization coverage.

Use of Information Technology: A study by Balogun MR et al from an urban setting in Lagos Nigeria identified the use of mobile phone reminders via short messaging system (SMS) and or telephonic reminders to be superior to the internet-based reminders for childhood immunization for mothers attending the immuni- zation clinic. (34)

A similar study by Akinrinade and colleagues from Ondo state Nigeria found out that majority of the caregiver prefer to receive SMS reminders for immunization at any given time. The study participants also comprise of significant $(42.8 \%)$ rural dwellers. (35) Both studies of Balogun MR et al [34] and Akinrinade and colleagues (35) demonstrated that post-secondary education of mothers/caregivers were predictors of mobile telephone ownership.

Even though, Africa witnesses the widespread introduction of the Global System Mobile communication (GSM) service in the last 20 years. There is still a critical underserved population that still lack access to this modern method; however this does not underscore its applicability in those that have access. The GSM providers could easily be approached for customized reminders on Measles vaccination that can be tailored down to the preferred language of the caregiver. (35)

The Balogun MR et al (34) and Akinrinade and colleagues (35) further bring to the fore the necessity of girl child education which must be looked holistically as an indirect means of achieving the Measles elimination target especially for African countries. Bhatti et al (36) from Pakistan used an innovative data mining algorithm for one health facility to characterize and track child immunization status from hospital based registers. This was coupled with a geographic information system that classifies regions based on red for good immunization coverages or green for poor imm unization coverages. This approach helped in planning unique vaccination campaigns to target the underserved areas coupled with education to caregivers.(36)

\section{Conclusion}

These review focused on newer innovations on measles vaccine delivery such as the microneedle patches, pulmonary/aerosol vaccination, thermostable vaccine, mono-dose prefilled vaccine delivery. Other areas involved given considerations for vaccine delivery to infants at age less than 9 months and given second dose of measles vaccination. Vitamin A supplementation, community engagements and use of information technology improves measles vaccine coverage. These innovations could be tailored to meet the specific demands and economic reality of populations in the sub-saharan African.

\section{Reference}

1. Saleh JEA. Trends of measles in Nigeria: A systematic review. Sahel Med J 2016;19:5-11.

2. Odega CC, Fatiregun AA, Osagbemi GK. Completeness of sus pected measles reporting in a southern district of Nigeria. Public Health 2010;124:24-7.

3. WHO. Measles fact sheet. Available from www.who.int/newsroom/ fact-sheets/detail/measles (Accessed 11/11/2019).

4. WHO. Available from www.who.int/immunization/sage/ meetings/ 2019/october/3_Feasibility_Assessment_of_Measles_and_Rubella_ Eradication up̃datedSAGE.pdf/ (Accesse-d 11/11/2019)

5. Goodson JL, Chu SY, Rota PA, Moss WJ, Featherstone DA, Vijayaraghavan $\mathrm{M}$, et al. Research priorities for global measles 
and rubella control and eradication. Vaccine 2012: 6;30(32):4709 -16 .

6. WHO. www.who.int/immunization/sage/meetings/2016/october/3 Regional_vaccine_action_plans_2016_progress reports.pdf?ua $=\overline{1}$. $(12 / 11 / 20 \overline{19})$

7. Moher D, Liberati A, Tetzlaff J, Altman DG, The PG. Preferred Re porting Items for Systematic Reviews and Meta-Analyses: The PRISMA Statement. PLoS Medicine 2009;6(7):e1000097.

8. Adhikari BB, Goodson JL, Chu SY, Rota PA, Meltzer MI. Assessing the Potential Cost-Effectiveness of Microneedle Patches in Child hood Measles Vaccination Programs: The Case for Further Rese arch and Development. Drugs in R\&D 2016;16(4):327-38.

9. Sievers RE, Cape SP, Rebits L. Needle-free inhalable dry powder aerosol measles vaccine developed for pulmonary delivery with a puff haler DPI. American Journal of Respiratory and Critical Care Medicine 2015; 191| Cochrane Library [Internet] . Available from (Accessed 11/12/2019)

10. Low N, Bavdekar A, Jeyaseelan L, Hirve S, Ramanathan K,Andrews NJ, et al. A Randomized, Controlled Trial of an Aerosolized Vaccine against Measles. New England Journal of Medicine 2015;372(16): 1519-29.

11. Pagliusi S, Jain R, Suri RK, DCVMN Executive Committee Group. Vaccines, our shared responsibility. Vaccine 2015; 33(19):2197202.

12. WHO. Assessing the Programme suitability of vaccine candidates for WHO prequalification-revision 2014. Geneva, Switzerland: World Health Organization: 2014.

13. Chen and Kristner. Oppurtunities and Challenges of thermostable vaccines. Expert Rev Vaccines 2009;8(5):547-57.

14. LLoyd J. Technologies for vaccine delivery in the $21_{\text {st }}$ century. WHO 2000.

15 .Aaby P, Martins CL, Garly M-L, Rodrigues A, Benn CS, Whittle H. The optimal age of measles immunisation in low-income countries: a secondary analysis of the assumptions underlying the current policy. BMJ Open 2012 Jan 1;2(4):e000761

16. Woudenberg T, van der Maas NAT, Knol MJ, de Melker H, van Binnendijk RS, Hahné SJM. Effectiveness of Early Measles, Mumps, and Rubella Vaccination Among 6-14-Month-Old Infants During an Epidemic in the Netherlands: An Observational Cohort Study. The Journal of Infectious Diseases 2017 Apr 15;215(8): 1181-7.

17. Griffin DE, Par CH. Measles: old vaccines, new vaccines. Current Topics in Microbiology and Immunology 2009; 330:191-212.

18. Aaby P, Martins CL, Garly ML, Balé C, Andersen A, Rodrigues A, Ravn H, Lisse IM, Benn CS, Whittle HC. Non-specific effects of standard measles vaccine at 4.5 and 9 months of age on child hood mortality: randomised controlled trial. BMJ 2010; 341.

19. Jensen KJ, Søndergaard M, Andersen A, Sartono E, Martins C, Garly ML, Eugen-Olsen J, Ullum H, Yazdanbakhsh M, Aaby P, Benn CS. A randomized trial of an early measles vaccine at $4 \frac{1}{2}$ months of age in Guinea-Bissau: sex-differential immunological effects. PLoS One 2014; 9(5):e97536

20.Do VA, Biering-Sørensen S, Fisker AB, Balé C, Rasmussen SM, Christensen LD, Jensen KJ, Martins C, Aaby P, Benn CS. Effect of an early dose of measles vaccine on morbidity between 18 weeks and 9 months of age: a randomized, controlled trial in Guinea-Bissau. The Journal of Infectious Diseases 2017; 215(8): 1188-96.

21.Martins C, Garly ML, Bale C, Rodrigues A, Njie-Jobe J, Benn CS, Whittle $\mathrm{H}$, Aaby P. Measles virus antibody responses in children randomly assigned to receive standard-titer Edmonston-Zagreb measles vaccine at 4.5 and 9 months of age, 9 months of age, or 9 and 18 months of age. The Journal of Infectious Diseases 2014a; 210(5):693-700.

22.Martins CL, Benn CS, Andersen A, Balé C, Schaltz-Buchholzer F,
Do VA, Rodrigues A, Aaby P, Ravn H, Whittle H, Garly ML. A randomized trial of a standard dose of Edmonston-Zagreb measles vaccine given at 4.5 months of age: effect on total hospital ad missions. The Journal of Infectious Diseases 2014b; 209(11): 1731-8.

23. Njie-Jobe J, Nyamweya S, Miles DJ, van der Sande M, Zaman S, Touray E, Hossin S, Adetifa J, Palmero M, Burl S, Jeffries D. Immunological impact of an additional early measles vaccine in Gambian children: responses to a boost at 3 years. Vaccine 2012; 30(15):2543-50.

24. Fisker AB, Nebie E, Schoeps A, Martins C, Rodrigues A, Zakane A, Kagone M, Byberg S, Thysen SM, Tiendrebeogo J, Coulibaly B. A two-center randomized trial of an additional early dose of measles vaccine: effects on mortality and measles antibody levels. Clinical Infectious Diseases 2018; 66(10):1573-80.

25. Manakongtreecheep K, Davis R. A review of measles control in Kenya, with focus on recent innovations. The Pan African Medical Journal 2017;27 (Supp 3):15.

26. Turner N. Global Status of MCV2: Time to remove the introduction criterion? Geneva, Switzerland: SAGE Working Group on Measles \& Rubella, 2016 Aug. Available from https://www.who.int/immuni zation/sage/meetings/2016/october/Session6-MCV2-Introductioncriteria.pdf. (Accessed 22/12/2019)

27. Brønd M, Martins CL, Byberg S, Benn CS, Whittle H, Garly ML, Aaby $P$, Fisker $A B$. Randomized trial of 2 versus 1 dose of measles vaccine: effect on hospital admission of children after 9 months of age. Journal of the Pediatric Infectious Diseases Society 2018; 7(3):226-33

28. Martins C, Garly ML, Bale C, Rodrigues A, Benn CS, Whittle H, Aaby P. Measles antibody levels after vaccination with EdmonstonZagreb and Schwarz measles vaccine at 9 months or at 9 and 18 months of age: a serological study within a randomised trial of different measles vaccines. Vaccine 2013; 31(48):5766-71.

29. Gera T, ShahD, Garner P, Richardson M, Sachdev HS. Integrated management of childhood illness (IMCI) strategy for children under five. Cochrane Database of Systematic Reviews 2016, Issue 6. Art. No.: C D 010123 . Available from www.cochranelibrary.com (Accessed 22/112/2019)

30. Reid RS, Smith EA. Going national with EPI in Nigeria. Assign ment Child 1984; (65-68):179-205.

31. Pagliusi S, Ting C-C, Lobos F, Datla M, Gao S, Homma A, et al. Vaccines: Shaping global health. Vaccine. 2017 Mar14;35(12): 1579-85.

32. Saeterdal I, Lewin S, Austvoll-Dahlgren A, Glenton C, MunabiBabigumira S. Interventions aimed at communities to inform and/ or educate about early childhood vaccination. Cochrane Database of Systematic Reviews 2014;11: CD010232. (Accessed 24/12/2019).

33. Fu LY, Zook K, Gingold JA, Gillespie CW, Briccetti C, Cora- Bramble $D$, et al. Strategies for improving vaccine delivery: a cluster-ran domized trial. Pediatrics, 2016; 137(6). Available from: https://www.cochranelibrary.com/ (Accessed 25/12/2019).

34. Balogun MR, Sekoni AO, Okafor IP, Odukoya OO, Ezeiru SS, Ogunnowo BE, Campbell PC. Access to information technology and willingness to receive text message reminders for childhood immunisation among mothers attending a tertiary facility in Lagos, Nigeria. S Afr J CH 2012;6(3):76-80.

35. Akinrinade OT, Ajayi IO, Fatiregun AA, Isere EE, Yusuf BO. Ownership of mobile phones and willingness to receive childhood immunisation reminder messages among caregivers of infants in Ondo State, south-western Nigeria. S Afr J Child Health 2018;12 (3):111-116.

36. Bhatti UA, Huang $M$, Wang $H$, Zhang $Y$, Mehmood A, Di W. Recommendation system for immunization coverage and monitoring. Human Vaccines \& Immunotherapeutics 2018:2;14 (1):165-71. 